\title{
Digital Humanities in Sweden and Its Infrastructure: Status Quo and the Sine Qua Non
}

\author{
Koraljka Golub, institute; Department of Library and Information Science, School of Cultural \\ Sciences, Faculty of Arts and Humanities, Linnaeus University, Sweden \\ E-mail: koraljka.golub@lnu.se \\ Elisabet Göransson, Centre for Theology and Religious Studies and Centre for Languages and \\ Literature, Lund University \\ E-mail: elisabet.goransson@lu.se \\ Anna Foka, Digital Humanities Uppsala (DH Uppsala), Department of ALM, Faculty of Arts, \\ Uppsala University and Humlab, Umeå University \\ E-mail: anna.foka@abm.uu.se
}

Isto Huvila, Department of ALM, Faculty of Arts, Uppsala University

E-mail: isto.huvila@abm.uu.se

\begin{abstract}
The paper offers a state-of-the-art overview of a number of Digital Humanities (DH) initiatives that have taken place in Sweden over the past decade. We identify two major developments that seem to be taking place within DH, with a specific focus on the infrastructural aspects of the development: 1) a strive to open up and broaden the research output; and, 2) multi-disciplinary collaboration and its effects. The two major components accentuate the new infrastructural patterns that are developing and the challenges these infer on universities. While current research is at large multi-disciplinary, developing infrastructures also enables the move towards post-disciplinarity, bringing the universities closer to the surrounding society. At five universities in Sweden individual-sited infrastructures supporting $\mathrm{DH}$ research have been built today. They are complemented by national and international infrastructures, thus supporting developments and tackling some of the major challenges. In the article the relations between individual disciplines, the question of multi- and post-disciplinarity and the field of Digital Humanities are discussed,
\end{abstract}


while stressing the factors necessary - sine qua non - for a fruitful development of the scholarly infrastructures.

\section{Introduction}

The field of Digital Humanities (DH) lies at the intersection of information and communication technologies (ICT) and humanities. The field and the concept are being continually (re)formulated by scholars and practitioners in a range of disciplines (see, for example, Gardiner and Musto, 2015; Schreibman, Siemens and Unsworth, 2016). In political discourse, the particular exploration of new ways of interactions between society and ICT from the humanities perspective has been purported to carry the potential to become a key success factor for the competitiveness and valuecreation on national (Vetenskapsrådet's Rådet för forskningens infrastrukturer, 2014 - Swedish Research Council's Board for Research Infrastructures) and European (European Commission, 2016) levels. In this paper DH is discussed primarily in the context of the definition formulated by Gardiner and Musto (2015, p. 4): 'harnessing computing power to facilitate, improve, expand and perhaps even change the way humanists work'.

The paper sets out to discuss prospects and challenges related to infrastructural aspects of Digital Humanities in Sweden. The scholarly society within the field of humanities has already been affected by the rapidly growing DH-related research, and the infrastructural implications of this development are significant. What impact does this have for the humanities in Sweden? In the article, we describe how the process in Sweden is characterised by infrastructural changes with a focus on public outreach and on the multi-disciplinary collaboration, similarly to processes in many other countries. The term infrastructure here encompasses various aspects of networks and scholarly organisations (for an overview, see: Foka, Misharina, Gelfgren and Arvidsson, 2018). Then, we identify the infrastructural changes that have to do with expanded scholarly communication networks, virtual and distributed research infrastructures of international institutions and initiatives and research collaborations across institutions and disciplines, as well as the increased focus on the open and interactive research output, bringing the academy and the citizen body closer together. Finally, we discuss specific local DH infrastructures at individual universities, harbouring scientific equipment and knowledge-based resources and specialized personnel, and their relations to the institutional structures of the academia and the established disciplines, touching upon questions about post-disciplinarity. The article does not aim to be an extensive overview providing a systematic analysis of $\mathrm{DH}$ related projects and initiatives in Sweden but rather to illustrate, discuss and reflect on a selection of pertinent themes relevant to these three perspectives. Furthermore, we do not specifically address the issue of education and related collaboration here which certainly also take place across disciplines and sectors.

The remainder of the paper is structured as follows: we first sketch the background: a brief historical overview of DH in Sweden, including a short terminological discussion; then we move on to discuss the aspects of the 1) scholarly infrastructure related to the $\mathrm{DH}, 2$ ) a strive to open up and broaden the research output, and 3) multi-disciplinary collaboration. The concluding section focuses on opportunities and inherent challenges of infrastructural change. 


\section{Background}

Technological progress, information and communication technologies, World Wide Web and digital infrastructures have become increasingly integrated in academic settings, including the humanities. The impact has been both direct through the appropriation of digital technologies in academic work and indirect through the escalation of technology use in the society as whole. This has fundamentally altered the way people think, live and work (see, e.g., Schwab, 2017). While the use of technology in the STEM field has a very specific function and may be measured by deliverables and experiments, the implementation of technology for arts and humanities in Sweden is still to some extent at an exploratory stage (see Nygren, Foka and Buckland, 2014).

Historically, Sweden was among the first countries to research and promote the use of computing technologies in disciplines outside natural sciences. The collaborations between technologists and arts and humanities scholars in Sweden date back to the 1960s, thus, period prior to the creation of the World Wide Web, as Nygren, Foka and Buckland (2014) showed in their review of historical DH units in Sweden. An early milestone was marked by Sture Allén when he created one of the first large electronic text corpora in a language other than English, Press-65, at University of Gothenburg in the 1960s (Borin, 2017). Following his work, since 1970s the Språkbanken (in English: Language Bank) project has been providing access to linguistic and statistical data about a diverse range of Swedish texts (ibid.). Further, in the World Wide Web era, specifically in 1997, the Nordic scholarly journal Human IT was launched with the purpose of reviewing and debating the relationship between the humanities and IT (Söderholm, 2017). In 1999, an interdisciplinary Humanities Lab (Humlab) was formed at Umeå University (Umeå University, 2017). At the same time, the project ITLIT (1999-2003) was initiated in Uppsala to study the effects of computerization on literature, with a focus on IT, storytelling and the literary system (Uppsala University, 2003). The number of scholars interested in humanities in a digital world has since multiplied, most significantly after Humanities Computing was rebranded as Digital Humanities in about 2005. The use of digital technologies in arts and humanities disciplines has extended to new areas of inquiry with new epistemologies, including the use of immersive environments (e.g., Ljungar-Chapelon, 2017; Slaney, Foka and Bocksberger, 2018) and the culture of making and gamification in collective memory organisations (Chapman, Foka and Westin, 2017).

In this article, we discuss digital research infrastructures for the humanities. The term infrastructure is used here broadly and moves beyond digital tools to include human networks and scholarly organisations as crucial types of resources and services that a DH research community uses to conduct research and promote innovation in the area; digital research infrastructures are thus of socio-technical nature (see Foka, Misharina, Gelfgren and Arvidsson, 2018).

$\mathrm{DH}$ infrastructures in Sweden are discussed in relation to aspects of multi-disciplinarity and post-disciplinarity. While the term inter-disciplinarity indicates collaboration between existing disciplines, mostly resulting in a study in which analyses made by scholars from different disciplines are integrated in the research outcome, it seems to us that the term multi-disciplinarity is more appropriate to the current status of $\mathrm{DH}$ in Sweden, signifying that a number of disciplines 
are being applied to a certain object of study, resulting in complementary analyses performed within each discipline. The effects of the changes we perceive within the traditional departmental structures and the developments of new infrastructures generate a new, post-disciplinary pattern within most universities in the sense that the transformation of the structure in itself may result in a new praxis of inquiry and a more problem-oriented approach, that is not primarily based on the notion of the disciplines per se.

\section{The National and International Scholarly Infrastructure Related to the Digital Humanities}

It is not just the digital that transforms - infrastructures and strategies are important, too (see, e.g., Kane et al. (2015)). At the national level, Sweden has established Digisam, the Swedish secretariat for national coordination of digitisation, digital preservation and digital access to cultural heritage, which serves as an inter-organisational platform for coordination of the digitisation of cultural heritage in Sweden. Because of the nature of national and private funding schemes as well as international collaboration (e.g., Humlab, Umeå with Stanford since 2008), Sweden has been early in the implementation of digital large-scale infrastructures for arts and humanities. For over ten years now, the National Bank of Sweden Tercentenary Foundation (in Swedish: Riksbankens Jubileumsfond), which focuses on projects within the humanities and social sciences, has had a call for proposals titled Programme and Infrastructure for Research, allocating almost four million euros each year. The Swedish Research Council has been granting large projects related to research infrastructures for several years, too. For example, it mandates the Swedish National Data Service (SND) whose role is to support the accessibility, preservation, and re-use of research data and related materials, including the humanities research data.

Furthermore, with the ambition of linking national scholarly DH networks to international ones, the Swedish CLARIN (Common Language Resources and Technology Infrastructure), a European Research Infrastructure Consortium (ERIC) was established in 2015. It aims at making language-based materials available as primary research data in humanities and social sciences and develops language technology as an e-research tool playing a major role in DH (Borin et al., 2017). Moreover, since 2016 when Linnaeus University joined DARIAH, another ERIC infrastructure for arts and humanities scholars working with computational methods, discussions have taken place within Sweden to strive for national membership (Golub, 2018) and a regional collaboration was started, formalized as the Nordic Hub of DARIAH (Golub et al., 2017). Digital Humanities in Nordic Countries (DHN), an associated organization to EADH (European Association for Digital Humanities), established in 2015, provides a forum for Nordic collaboration, largely through its annual conferences.

Scholarship in Digital Humanities is typically internationally oriented and also transgresses organisational borders in the academy. The Swedish landscape is not different from other countries in that respect; also, individual projects often take advantage of open access tools and infrastructure communities. For example, for Digital Periegesis, a GIS visualization of Pausanias's description of Greece (see www.periegesis.org), funded by the Marcus and Amalia Wallenberg Foundation for three years), places the emphasis on the reuse and extension of data and tools that have already 
been produced and have a community around them. Project members use the text of the Periegesis from the Perseus Classical Library, openly licensed (in CC-BY) and for free reuse. The second key element is the platform in and with which the text is semantically annotated: the open-source Webbased platform Recogito, initiated by an international socio-technical community and infrastructure for Linked Open Geodata in the Humanities that is funded by the Andrew Mellon Foundation (Pelagios Commons, 2019). Recogito enables the user to easily upload texts (as well as images and tables), which can then be annotated with additional information. As part of a growing community, Recogito currently has circa 3,000 regular users, who have produced circa 1.9 million annotations. Third, and following on from this: semantic annotation in Recogito conforms to a Linked Open Data model for connecting other online resources. It is thus possible to relate Pausanias's deep description of various sites (the Athenian Agora, or Corinth, for example) to the archaeological data found there and the plans of them produced in contemporary research.

In addition to the above mentioned national and international infrastructures and funding schemes, many DH projects undertaken in Sweden are also funded within ordinary research funding programmes. The types of projects and the research output are normally perceived as primarily scholarly projects with a particular focus on direct research output from each project. Typical for DH-related projects is that they harbour scholars from different disciplines. Their published results are to a large extent in the traditional channels within the individual disciplines, and the publications are mainly single authored, although multi-authored, interdisciplinary publications are certainly also common. In other words, the research output is mainly multidisciplinary. A general observation is that it is sometimes unfortunate that there is a pronounced expectation of direct research output from each infrastructural project: in some cases, this is an impediment for building up a solid base for further research, that requires a lot of resources. Resources cannot normally be allocated for basic research that cannot and should not render so much direct scholarly output before the research data have been assembled, platforms have been built, corpora have been created by applying standards, and so on.

\section{Strive to Open up and Broaden the Research Output}

The organization of cross-sectoral collaboration and outreach in DH differs between individual universities. At Linnaeus University, the framework for cross-sectoral collaboration has been set at a general level in its strategy document that emphasises cross-sectoral effort to address future societal challenges (Linnaeus University, 2014). The collaboration concerns both research and education and involves engagement with IT-companies, cultural heritage organizations and local municipalities. Examples include: promoting cultural events through an app in collaboration with an art organisation Nya Småland (in English: New Småland, Småland being the region in southeastern Sweden), applying learning technologies in museums (Center for Learning and Knowledge Technologies, 2016), exploring use scenarios of open government data with Växjö municipality, researching issues related to humanities research data curation in collaboration with university libraries at Lund and Linnaeus university, a collaboration with the Swedish National Library on 
automatic subject indexing, and projects within archaeology in collaboration with museums and IT companies. DH seminars, open to the general public, are also organized in order to communicate the projects and further enhance the outreach (Linnaeus University, 2019).

An example of another form of organising collaboration is the Getty Foundation project Ancient Itineraries (Ancient Itineraries, 2019), administered by Kings College London and involving scholars from Uppsala University and Humlab at Umeå University. It brings together scholars with hands-on skills as well as conceptual platform development in collaboration with Kings' College Digital Lab. A major outcome will be a Proof of Concept for art history objects with an interface geared towards three scholarly clusters: provenance, visualization and GIS.

A third example of how cooperation has been organised in Sweden is the collaboration between three major university libraries in Sweden (Uppsala, Lund, Gothenburg) joined by a number of other libraries, organizations and scholars to develop Alvin, a platform for digital collections and digitized cultural heritage (Alvin, 2019).

For individual DH projects in Sweden, it is typical to collaborate with cultural heritage institutions. A current example is the project Digital Models (Digitala Modeller, 2019), a collaboration between the Swedish National Museum of Science and Technology and Humlab at Umeå University, that aims at exploring the possibilities of digital technology in relation to industrialism's narratives about society, people and environments. The scholarly foundation of this project is that digital technology is opening up new ways of approaching old collections, and raising new questions and critical perspectives. The project aims to explore the specificity and potential of digitisation as a bridge between research, memory institutions and visitors from three different cultural heritage perspectives. The underlying project concept is that GLAM (galleries, libraries, archives and museums) institutions should not only digitise their collections but also make it possible for researchers and visitors to use - even to play with - their digitised cultural heritage using applications, tools and software.

\section{Multiple Disciplinary Collaboration and the Single-Sited Research Infrastructures}

Supporting and organising of DH activities varies between universities. Today five Swedish universities have DH-specific infrastructures in place: a) Humanities lab, Lund University, b) Humlab Umeå, c) Centre for DH Gothenburg, d) DH initiative at Linnaeus University, and e) Digital Humanities (DH) Uppsala. While at some universities $\mathrm{DH}$ is used as a platform to bring traditionally disparate disciplines and units together with an aim of promoting the university's DH research infrastructure as a host for emerging activities, the cross-unit and cross-disciplinary DH collaboration at others is hosted by the unit and discipline to which the project leader belongs. The single-sited research infrastructures, Humlab in Umeå, the Humanities Lab at Lund University and the Centre for Digital Humanities in Gothenburg and are similar to each other in that they integrate projects hosted by the infrastructure itself and act as consultants to projects hosted by scholars within the traditional disciplines. 
In Lund, different disciplines in the humanities harbour many initiatives, projects, and a lab that, according to the broad definition of DH in this paper, could easily fit the DH title. The Humanities Lab, established in 2007, is a scholarly interdisciplinary department for research technology and training. The Humanities Lab acts both as a partner in projects led elsewhere, and hosts projects independently. The collaboration is not restricted to the humanities proper, but extends over faculty borders. No less than around 500 scholars are currently using the Humanities Lab or collaborating with Humanities Lab staff. Another unit is the field of study titled Digital cultures which constitutes one of four research nodes at the Department of Arts and Cultural Sciences, the other three being Analogue culture, EcoCultures and Medical humanities. Within this framework, Digital cultures focus on cultural perspectives of the on-going digitisation of society. This research node brings together disciplines to study different aspects of the digital, covering both contemporary and historic phenomena. Communication around digital tools and methods also takes place in various contexts across both disciplinary and faculty borders at Lund University. An informal interdisciplinary seminar on digital tools in the humanities was initiated in 2014; this type of communication brings different stakeholders in the field together, including scholars and teachers, librarians, archivists, IT-personnel, and the staff at the Humanities Lab.

At Lund University, the different units and persons involved in what is often defined as DH generally tend to avoid the label. The Humanities Lab focuses on technology and methods of different types, not necessarily only digital. The different projects hosted at the departments - in archaeology, theology, literature, languages etc. - are not primarily defined as DH projects proper either; they receive funding in competition with projects not focused or based on digital methods, tools and material, and exist in parallel to one another. Moreover, the digital cultures research node studies aspects of digitization of the society, that means, performs studies on communication, sociology and infrastructure of the societal change on a meta-level. Seminars and workshops focus on the tools and methods developed, which may many times cross the faculty borders. The same goes for the Humanities Lab. Therefore, the Digital Humanities as an umbrella term for the field in general is probably not referred to so much in the scholarly infrastructure in Lund as elsewhere.

The situation is somewhat different at Linnaeus University where the Digital Humanities Initiative (DHI) acts as a hub of common interests across faculties and disciplines, including archaeology, religion, film, literature, languages, linguistics, history, computer science, marketing, media technology, library and information science. The hub connects researchers at the university with external sectors as well as national and international colleagues. It organises seminars and guest lectures as well as education. Projects granted are hosted by the project owners. A DH strategy is hosted by the Faculty of Arts and Humanities to sustain the efforts.

The interdisciplinary DH initiative in Uppsala provides yet another example of a crossfaculty approach to support and bring together people and research groups who are already working with and in Digital Humanities or who have developed a more recent interest in the field. DH Uppsala (Uppsala University, 2018) was established in 2018 and is funded by two research areas at the Faculty of Arts and Humanities and the Faculty of Computer Science. For the first two years of its establishment it aims at catering to Digital Humanities researchers at Uppsala 
University with a focus on existing DH projects and following the work of Forum för Digital Humaniora that had been administered by the University Library. Even if the term Digital Humanities has not been used at the university level until rather recently, many Uppsala researchers have been working in the area for years, some for decades. The Faculty of Languages has a long history in research in computational and corpus linguistics, the Department of History and Archaeology and Ancient history have engaged in several projects in the area, and together with groups in various other departments ranging from ALM (Archive, Library and Information, Museum and Cultural Heritage Studies) to Information technology, Literature, History of Science and Ideas, Game Design, Gender Studies and Theology, the network of Digital Humanities research covers large parts of the university. A somewhat unique aspect in the Swedish context is that the Uppsala University Library has taken an active role in the field together with other cultural heritage institutions of the university and collaborates with $\mathrm{DH}$ Uppsala for the planning of seminars and workshops.

\section{The Sine Qua Non for Scholarly Infrastructures?}

There is plenty of evidence that national and international scholarly networks and infrastructures in the DH field are strong and they also provide good opportunities to further develop multidisciplinary collaboration that is necessary for the DH-related research. Even if sometimes criticised, it is doubtful that the different approaches to organizing $\mathrm{DH}$ research at different universities are impeding its development. It is also apparent that very different types of networks can be successful. But there are certain problems and preconditions that can be identified across the Swedish DH.

One of the problems is that the networks are not always anchored all the way down to individual scholars within the included disciplines. This applies especially to international initiatives and their rapport with specific local research undertakings. There is a certain degree of a lack of transparency how to get involved in the broad multinational initiatives and how to link specific projects to their work. A further consideration of how to unleash the local potential of these scholarly international and DH-related networks is a challenge that requires attention. An example of the challenges of linking the local work to large international networks is the collaboration initiated at Linnaeus University to join DARIAH. Currently, an effort is being made to disseminate DARIAH newsletters and to encourage researchers to engage in DARIAH activities but the collaboration is clearly hampered by the difference of scale and distance between the local and, in the case of DARIAH, European contexts. The unsustainable efforts of this type could be addressed by national Swedish membership in DARIAH, or, at the level of Linnaeus University, based on the strategy for Digital Humanities being drawn at the Faculty of Arts and Humanities.

An opportunity in this line of work is also the possibility to attract interest of the society outside of academia. This is testified, for example, by the cross-sectoral collaboration that the Linnaeus University is building up, and the broad network associated with their Digital Humanities Initiative. The prospects for collaborative projects incorporating academic and applied research are improved in these types of networks. For a long time, the fulfilling of the task of public outreach 
assigned to universities in Sweden has been achieved in the form of printed publications within popular science: books, journals, and in the form of public lectures. What we now see is a much more embedded and deeper form of cross-sectoral collaboration which might imply that we do not any more have a top-down flow of information and influence from the academy to the citizen body, but a much more interactive and also continuous flow back and forth, which eventually brings the academy and the citizen body closer together.

Besides cross-disciplinary collaborations, the evolution of the individual disciplines within the DH area is another important aspect of the new infrastructural landscape related to DH that we see. The character of the different humanities fields varies, from the more methods-oriented disciplines to disciplines focused on the study of a specific thing, phenomenon or perspective. Digital tools, techniques and methods developed within the Digital Humanities field are used as part of research within a broad range of disciplines. Sometimes, Digital Humanities are seen as a discipline in its own right, although this is being debated and questioned (Lundblad, 2017). The advocates for maintaining the $\mathrm{DH}$ as a label instead of working harder to integrate DH-related research more directly with the disciplines, often point to the fact that the infrastructural and longterm commitments that are more or less required to ensure the quality of projects started in the field do not match well with the existing infrastructures directly associated with individual disciplines and their separate organisations. This pertains to leadership strategies as well as discussed later in this text.

Moreover, there are concerns related to the fact that there are specific funds allocated to DH related projects that are being addressed in the scholarly society. It seems as if scholars within the $\mathrm{DH}$ area are generally in agreement that the $\mathrm{DH}$ should be naturally implemented in the traditional disciplines even though DH related projects typically include scholars within different disciplines. What is indeed very important is the awareness of the scholarly output, the deliverables and long-term sustainability of the results from such projects, since the ones that are not hosted by a DH infrastructure may later benefit from this infrastructure anyway. It is then quite important to define the stakeholders concerning the plan for the research outcome already from the start. This is not always crystal clear, but remains vital for the success and usefulness of concluded DH projects for the scholarly society. The infrastructures supporting projects that involve digital tools, hosting software and corpuses have been built up in different ways in the different universities in Sweden. It could be detrimental if the projects associated with Digital Humanities would be seen as competing with others that would not define themselves as pertaining to the field at all. A too narrow categorization of fields and initiatives could lead to an emergence of unnecessary new boundaries between disciplines.

At the other end of the spectrum, it is healthy to ask if the current forms of multidisciplinary collaboration could eventually lead to disciplinary convergence? For certain, the type of deliverables from these projects are to a higher extent co-authored by scholars belonging to different disciplines; resources produced as results of DH projects are almost always multidisciplinary and not interdisciplinary to the same extent. Still, even if we do not necessarily see (or risk, depending on the perspective) a disciplinary convergence, different disciplines are certainly 
in closer communication through the collaborative work now, and in effect the borders between the individual disciplines at least tend to become less strict. However, most scholars stress the importance of keeping the disciplinary specializations with their specific methodologies and theories that are improved by the methods and tools developed within the DH area.

Independent of the opportunities, it seems however, that the bottom line and the most indispensable ingredient in determining whether the obstacles are overcome and opportunities seized is leadership, and the way that the new landscape of projects and initiatives are integrated in the scholarly society. With the rise in complex, interdependent, and emergent challenges, effective change to secure a brighter future will require transformative, collaborative leaders who can effectively lead cross-sector collaborations. For the leadership it is quite important to identify how the disciplines function within the DH field, what types of research questions, materials and method clusters there are, leading to the state where it is clear how to best ascertain that DH related projects are started only when the deliverables and sustainability can be guaranteed.

Apart from scholarly leadership, there is also a need to focus on infrastructural leadership to facilitate the scholarly and scientific work to promote the development of scholarly standards within the $\mathrm{DH}$ area providing resources to facilitate the collaboration leading to standards not only for peer-reviewed scholarly digital publications and resources but also for the long-term commitment to the maintenance of other resources related to cross-sectoral projects. The university leadership should collaborate with other relevant stakeholders in facilitating this by allocating the necessary resources. It is also important to develop the scholarly standards relevant for different strands of research. Many standards may be post-disciplinary in the sense that they are related not primarily to the institutional and disciplinary structures; others in the sense that they are focused on certain ages or main areas, such as the recently launched Medieval Academy of America Database of Medieval Digital Resources (Medieval Academy of America, 2019), including only peer-reviewed resources according to the clearly defined standards.

The changes described in this article represent developments that were not possible before the emergence of DH in the sense that the types of infrastructures described would not have emerged otherwise. It helps in affirming the value of humanities in the eyes of the citizen body, and of academic practices in general. There are challenges, and the relation between the local infrastructures and the disciplines are central to the full integration of the scholarly infrastructures in the institutional and departmental organisations, in order to eliminate the gap that is sometimes perceived, and to promote further development of the vital scholarly networks. 


\section{References}

Ancient Itineraries. (2019). Ancient Itineraries: Exploring Digital Art History. https://ancientitineraries.org (accessed 22 March 2019)

Alvin. (2019). Alvin: Platform for Digital Collections and Digitized Cultural Heritage. https://www.alvin-portal.org (accessed 20 March 2019)

Borin, L. (2017). Språkbanken: The Swedish Language Bank. https://svenska.gu.se/english/research/sprakbanken (accessed 20 March 2019)

Borin, L. et al. (2017). Swe-Clarin: Language Resources and Technology for Digital Humanities. http://ceur-ws.org/Vol-2021/paper2.pdf (accessed 20 March 2019)

Center for Learning and Knowledge Technologies. (2016). CeLeKT: Center for Learning and Knowledge Technologies. http://www.celekt.info (accessed 20 March 2019)

Chapman, A., Foka, A. and Westin, J. (2017). What is Historical Game Studies?, Rethinking History 20:4, pp. 358-71.

Digital Periegesis. (2018). The Digital Periegesis: Tracing the Places of Ancient Greece and the Stories Associated with Them. http://www.periegesis.org (accessed 20 March 2019)

Digitala Modeller. (2019). Digitala modeller. http://www.digitalamodeller.se (accessed 20 March 2019)

European Commission. (2016). Horizon 2020: Social Sciences and Humanities. https://ec.europa.eu/programmes/horizon2020/en/area/social-sciences-humanities (accessed 20 March 2019)

Gardiner, E. and Musto, R. G. (2015). The Digital Humanities: A Primer for Students and Scholars. Cambridge: Cambridge University Press. 
Golub, K. (2018). DARIAH-SWE: Discussion Around an Initiative to Start a National Organization. https://lnu.se/en/research/searchresearch/digital-humanities/meeting-gothenburgfeb-21-2018/ (accessed 20 March 2019)

Golub, K. et al. (2017). Current Efforts, Perspectives and Challenges Related to Digital Humanities in Nordic Countries. http://ceur-ws.org/Vol-2021/paper12.pdf (accessed 20 March 2019)

Kane, G. C., Palmer, D., Phillips, A. N., Kiron, D. and Buckley, N. (2015). Strategy, Not Technology, Drives Digital Transformation, MIT Sloan Management Review and Deloitte University Press, 14.

Linnaeus University. (2014). A journey into the Future: Vision and Strategy 2015-2020. https://nu.se/globalassets/dokument---gemensamma/universitetsledningenskansli/a_journey_into_the_future_2015-2020.pdf (accessed 20 March 2019)

Linnaeus University. (2019). Digital Humanities Initiative. https://lnu.se/en/digihum (accessed 20 March 2019)

Ljungar-Chapelon, M. (2017). Virtual Bodies in Ritual Procession - Digital Co-production for Actors and Interpreters of the Past, Internet Archaeology 46. http://intarch.ac.uk/journal/issue46/index.html (accessed 20 March 2019)

Lundblad, K. (2017). Digital humaniora - en pleonasm i den digitala kulturen, In Erixon, P.-O. and Pennlert, J. (eds), Digital humaniora - humaniora i en digital tid. Daidalos: Gothenburg, pp. 27-51.

Medieval Academy of America. (2019). Medieval Academy of America: Database of Medieval Digital Resources. http://www.themedievalacademyblog.org/maa-database-of-medieval-digitalresources/ (accessed 20 March 2019) 
Nygren, T., Foka, A. and Buckland, P. (2014). Digital History in Sweden. In H / Soz / Kult: Kommunikation und Fachinformation für die Geschichtswissenschaften. http://hsozkult.geschichte.hu-

berlin.de/index.asp?type $=$ diskussionen $\&$ id $=2402 \&$ view $=$ pdf $\& p n=$ forum $\quad($ accessed 20 March 2019)

Pelagios Commons. (2019). Recogito. https://recogito.pelagios.org (accessed 20 March 2019)

Schreibman, S., Siemens, R. and Unsworth, J. (2016). A New Companion to Digital Humanities. (2nd ed.). Malden, MA; Chichester, West Sussex, UK: Wiley-Blackwell.

Schwab, K. (2017). The Fourth Industrial Revolution. London: Portfolio Penguin.

Slaney, H., Foka, A. and Bocksberger, S. (2018). Ghosts in the Machine: An Experiment in Distributed Reception, Digital Humanities 12:3. http://digitalhumanities.org/dhq/vol/12/3/000395/000395.html (accessed 20 March 2019)

Söderholm, J. (2017). 20 Year Anniversary Report \& Issue 13.3 Editorial, Human IT, 13(3). https://humanit.hb.se/article/view/641 (accessed 20 March 2019)

Umeå University. (2017). Humlab. https://www.umu.se/en/humlab/ (accessed 20 March 2019) Uppsala University. (2003). IT, berättandet och det litterära systemet (ITLIT). http://www.littvet.uu.se/forskning/avdelningen-for-litteratursociologi/forskningsprojekt/itberattandet-och-det-litterara-systemet/ (accessed 20 March 2019)

Uppsala University. (2019). Digital Humanities Uppsala. http://uu.se/digitalhumanities (accessed 20 March 2019)

Vetenskapsrådet's Rådet för forskningens infrastrukturer. (2014). Områdesöveriskt för forskningens infrastrukturer. 
https://web.archive.org/web/20150419163250/http://www.vr.se/download/18.2302fa711489c479 8d4a35fa/1411461229423/Samtliga+områden+infrastruktur.pdf (accessed 20 March 2019) 